\title{
The Relationships Between the Emotional Intelligence and Job Satisfaction: Emprical Findings From Higher Education Institution in Malaysia
}

\author{
Muhammad Masroor Alam* \\ Associate Professor, Faculty of Management and Social Sciences \\ Institute of Business and Technology (BIZTEK) \\ Karachi-Pakistan
}

\begin{abstract}
This study seeks to investigate the relationship between emotional intelligence (EI) and job satisfaction among the administrative staff in higher education institution in Malaysia. The literature suggests that employee skills in general and emotional intelligence in particular, play a significant role in the success of completing their goals in the workplace and hence perceived greater job satisfaction. This argument, despite its popularity, remains elusive. This can be attributed to the fact that although a few studies have provided evidence to support this argument, it has not received an appropriate empirical investigation at all level of employees and their work role in different industrial setting. This study attempts to narrow this gap by empirically examining the extent to which employees at university's non teaching roles with a high emotional intelligence employed in public sector organizations develop positive work attitudes, behavior and outcomes. And therefore they perform well to sustain job satisfaction.

Using a sample of 120 non teaching employees in University Perlis Malaysia, their EI were captured using a five point likert scale. Correlation statistics revealed that EI with its three dimensions, appraisal, utilization and regulation were associated significantly and positively with job satisfaction. The linear regression analysis result further confirmed the predictor nature of the three dimension of emotional intelligence for the job satisfaction.
\end{abstract}

Keywords : Emotional intelligence, job satisfaction, higher education

\section{INTRODUCTION}

Job satisfaction has drawn great attention from organizational behavior researchers (Dormann \& Zapf, 2001; Gerhart, 2005; Heller, Judge \& Watson, 2002; Staw \& CohenCharash, 2005; Robbins, 2005). While employees changing jobs multiple times during their careers, job satisfaction becomes such an important research topic of scientific investigation. A better understanding of job satisfaction and its predictors could greatly assist supervisors, managers and administrators to communicate with employee relations and subsequently facilitate organizational change.

Research suggested that recent studies tend to focus more on personal disposition with relation to job satisfaction in the work place (Staw, 2004). For example, several studies have reported that there were significant relationships between self-esteem, employee motivation and job satisfaction; however, these studies have neglected to examine two potentially important predictors of job satisfaction-emotional intelligence and trust (Dormann \& Zapf, 2001; Dent, 2001).

* The material presented by the author does not necessarily portray the viewpoint of the editors and the management of the Institute of Business \& Technology (BIZTEK)

*Muhammad Masroor Alam : m_alam_muhammad@yahoo.com

C JMSS is published by the Institute of Business and Technology (BIZTEK).

Main Ibrahim Hydri Road, Korangi Creek, Karachi-75190, Pakistan. 
Mayer and Salovey (1997) defined emotional intelligence as an individual's ability to perceive, express, understand and regulate emotional responses both internally and in others. An employee with high emotional intelligence is able to respond appropriately to workplace stress and to the emotional behavior of his or her coworkers. These abilities are anticipated to greatly enhance job satisfaction. Moreover, research has already shown that emotional intelligence leads to high job performance (Bar-On, Handley \& Fund, 2006; Druskat, Sala \& Mount, 2006), long-term mental health (Ciarrochi \& Godsell, 2006), better outcomes in work groups and leadership qualities (Lopes, Cote \& Salovey, 2006), and organizational success (Mount, 2006).

Since emotions of employee playing a significant role in organization's life, the need to study emotions and (emotional intelligence) is obvious (Harrod \& Scheer, 2005). Despite the dramatic increase in the number of researches in emotional intelligence, the topic has not been seen as sufficient exploration relatively to other areas such as cognitive intelligence, mental health and mental capabilities (Harrod \& Scheer, 2005).

Goleman (1996) claimed that emotional intelligence, not intelligence quotient (IQ) is the true measure of human intelligence. He argued that qualities such as understanding one's emotions, recognizing and empathizing with other's emotions and regulating one's emotions are much more important than IQ. Consistent with the argument of the Goleman (1996), as a matter of fact, people's life experience is greatly influenced by how they feel and perceive which in turn can play a major role in determining their level of satisfaction. A study done by Fisher (2006) on mood, emotions and job satisfaction revealed that mood and emotions accounted for unique variance for overall job satisfaction.

In the past, emotions were ignored in the study of organizational behavior. The workplace was considered a rational environment, this vision continued till research findings have shown the essential function of emotions in explaining many workplace phenomena and organizational outcomes. Several empirical studies have shown the wide scope of applicability of emotional intelligence in many workplace issues which their implications have considerable interest to the organizations. To mention few for example, performance, leadership effectiveness, work team cohesiveness, organizational change (Rosete \& Ciarrochi, 2005; Rapisarda, 2002; Vakola, Tsausis, \& Nikolaou, 2004).

According to Goleman (1996) and Fisher (2006), rational intelligence is not enough to succeed in life. In fact, it is emotional intelligence rather than intelligence quotient which has recently captured the public's attention. Research has shown that, it is no longer considered a good predictor of how effective an employee will be in work and life; rather it suggests that is a better predictor in determining employee's effectiveness.

Therefore this study was conducted to explore more of EQ and in exploring its claimed role in occupational environment. The ability of the emotional intelligence in predicting other outcomes in the workplace is calling for further examination. A great deal of researches have been carried out on relationships between job satisfaction and situational factors, such as task attributes, pay, promotion, supervision, and working conditions but not the relationship between emotional intelligence and job satisfaction. In fact, there are very few scientific or empirical research in this area. It seems that there might be other factors influencing job satisfaction of employees are overlooked or have not received adequate exploration in the workplace. Thus, the present study is an effort to empirically assess the efficacy of using emotional intelligence as a predictor (independent variable) of job satisfaction (dependent variable) among the employees of University Malaysia Perlis.

\section{OBJECTIVE OF THE STUDY}

The main objectives of the present study are:

1. To examine the association between the three dimensions of emotional intelligence 
and job satisfaction.

2. To examine the effect of he three dimensions of emotional intelligence on job satisfaction.

\section{LITERATURE REVIEW}

\section{Emotional Intelligence}

Mayer and Salovey defined emotional intelligence as "the ability to perceive and express emotion, assimilate emotion in thought, understand and reason with emotion, and regulate emotion in self and others" (1997, p. 401). This concept emphasizes the importance of self-awareness and the ability to re-evaluate and balance a person's intellect and emotion within a typical daily life. Zeidner, Matthews and Roberts (2004) summarized emotional intelligence as "a mélange of competencies and general dispositions for adaptive personal functioning and coping with environmental demands" (p. 375). Emotional intelligence is related to "emotion, motivation, personality traits, temperament, character, and social skills" (Zeidner et al., 2004, p. 375).

Goleman has published best-sellers on emotional intelligence $(1995,1998)$. He suggested that emotional intelligence is composed of self awareness, self-management, social awareness and social management (1998). Hence, emotional intelligence allows individuals to not only recognize their own emotions in and outside of strictly intellectual situations, but also to recognize the emotions of others. As people understand their emotions and those of others, they are then able to better control and/or regulate those emotions.

Zeidner, Matthews and Roberts (2004) stated that emotional intelligence "designates the potential to become skilled at learning certain emotional responses ... that can determine a person's potential for learning practical job-related emotional and social skills" (p. 377). The ability to emotionally gauge oneself and one's coworkers fosters the necessary social skills to succeed in a professional context. Emotional intelligence helps create a positive sense of well-being and thereby enhanced performance outcomes (Druskat, Sala \& Mount, 2006).

Goleman, Boyatzis and McKee (2002) emphasized that leaders should lead with emotional intelligence. In their National bestseller, Primal Leadership, they focused on two competence of emotional intelligence: personal competence and social competence. They suggested that personal competence shapes how individuals manage themselves while social competence determines how they manage others and relationships. Boyatzis and McKee (2005) continued their research on primal leadership, showing how "leaders can create resonance in their relationships, their teams, and their organizations". They pointed out that great leaders are emotionally intelligent and they are "awake, aware, and attuned to themselves, to others, and to the world around them. They commit to their beliefs, stand strong in their values, and live full, passionate lives" (Goleman , Boyatzis \& McKee, 2002).

Emotional intelligence plays a large role in shaping individuals. Goleman (1998) and (1999) explained that emotional intelligence creates passion, confidence, friendliness, motivation, pride, and energy in individuals.

The ability to transmit these same emotions to others offers emotionally intelligent people advantages over others in interpersonal and organizational contexts. Zeidner, Matthews and Roberts claimed that people of higher emotional intelligence succeed at communicating their goals, ideas, and intentions in more interesting and assertive manners. They suggested that emotional intelligence is related to the social skills necessary for teamwork. Together, these abilities contribute to a satisfying personal and professional life. This study focused on the most popular dimensions proposed by (Salaovy and Mayer, 1990). In this section a brief review and definitions of these three dimensions of emotional intelligence are presented. 
Salaovy and Mayer (1997) defined emotional intelligence as "the subset of social intelligence that involves the ability to monitor one's own and others' feelings and emotions, to discriminate among them and to use this information to guide one's thinking and actions". Later on, they refined and defined emotional intelligence as "the ability to perceive emotions, to access and generate emotions so as to assist thoughts, to understand emotions and emotional knowledge, and to reflectively regulate emotions so as to promote emotional and intellectual growth" (Salovey \& Mayer, 1990). A key construct in their definition that needed to explain is "emotions". According to Van and Kunda (1989) emotions are "ineffable feelings of the self-referential sort", and are comprehensively defined as "selfreferential feelings an actor (employee) experiences or, at least, claims to experience in regard to the performances he or she brings off in the social world". States of feeling refer to basic emotions (e.g. joy, love, anger) and social emotions (e.g. shame, guilt, jealousy, envy), as well as to related constructs as affect, sentiments and moods.

\section{THEORETICAL FRAMEWORK}

Salovey and Mayer (1990) argued that there is a set of three conceptually related mental processes - appraising and expressing emotions in the self and others, regulating emotion in the self and others, and using emotions in adaptive ways involving emotional information. The following are brief descriptions of the content and importance of these mental processes:

(1) Appraising and expressing emotions in the self and others. Individuals differ in the degree to which they are aware of their emotions (appraisal) and the degree to which the latter are verbally and non-verbally being expressed (George, 2000). Individuals who accurately appraise and express (perceive and respond to) their emotions are likely to be better understood by the people they work with, and they also have the potential to better lead and manage people when they are able to perceive the emotions of the people around them and to develop empathy - the ability to comprehend another's feelings and to re-experience them oneself (Salovey and Mayer, 1990).

\section{(2) Regulating emotion in the self and others.}

People differ in their ability to manage (monitor, evaluate, and adjust to changing moods) their emotions as well as in their ability to regulate and alter the affective reactions of others (Salovey \& Mayer, 1990). Regulation of one's own emotions and moods results in positive and negative affective states. Emotionally, intelligent individuals are adept at placing themselves in positive affective states, and are able to experience negative affective states that have insignificant destructive consequences. Emotionally smart people can induce a positive affect in others those results in a powerful social influence (charisma), an important component of leadership (Wasielewski, 1985).

\section{(3) Utilization of emotions of oneself and others:}

Individuals also differ in the ways (functional vs. dysfunctional) in which they utilize their emotions.

\section{Emotions can:}

- help in generating multiple future plans (flexible planning);

- improve the decision-making process due to a better understanding one's emotional reaction (creative thinking);

- acilitate cognitive processes such as creativity on the one hand and punctuality on the other hand (mood redirected attention); and

- enhance persistence regarding challenging tasks (motivating emotions) (Salovey \& Mayer, 1990).

\subsection{Job Satisfaction}

Employee job satisfaction is critical to organizational communication, since it is directly related to organizational outcomes. Job satisfaction can be conceptualized as an individual's 
attitude toward his or her job. Beginning in the late 1950s, researchers have sought to understand job satisfaction and conduct empirical studies to test their models. In a departure from conventional theories, Herzberg and his colleagues (Herzberg, Mauser \& Snyderman, 1959) proposed a typology in which separate groups of factors were proposed to independently influence job satisfaction and job dissatisfaction. This led to the development of their dual factor theory of job satisfaction. This theory proposes that job satisfaction and job dissatisfaction are independent constructs and not part of a single continuum. Thus, individuals not exhibiting job dissatisfaction may still not exhibit true satisfaction with their jobs.

Job satisfaction is based on individuals' experience which is associated with individuals' needs, expectation and benefits of their jobs (Locke, 1976). Dormann and Zapf (2001) stated that job satisfaction has become one of the most critically important and extensively research concepts in organizational psychology. These authors have speculated that job satisfaction can be significantly influenced by a wide variety of task characteristics including responsibility, task variety and communications/feedback mechanisms. Dormann and Zapf (2001) also reported the emergence of significant relationships between job satisfaction, absenteeism and other workplace behaviors.

Job satisfaction has been linked both to situational factors (sociological perspective) and personal factors (psychological perspective). Heller, Judge and Watson (2002) reported that situational factors include job-related conditions such as pay, opportunities for promotion, and working conditions and job characteristics such as task identity, task significance, skill variety, autonomy, and feedback. Research has provided consistent results to support the positive correlation between job satisfaction, job conditions, and job characteristics (Heller et al., 2002). Personal factors include personality disposition, traits, self-esteem, motivation, and emotions (Dormann \& Zapf, 2001). Heller et al., (2002) identified that such positive factors as high energy, pleasurable engagement, and enthusiasm are positively related to job satisfaction, while negative factors such as distress, unpleasant engagement, and nervousness are negatively related to job satisfaction. Several studies have confirmed that job satisfaction is directly related to personal affective disposition factors (Staw \& Cohen-Charash, 2005; Gerhart, 2005).

In short, a review of the literature suggests that job satisfaction is a critical variable in an organizational climate study. Although the variable has been studied to a great extent in past decades, there is a gap in terms of understanding of how the variable is related to emotional intelligence and trust. Both of these variables are critical to organizational communication and organizational outcomes. However in this study only emotional intelligence is considered for the investigation of the relationship between EI and job satisfaction.

\subsection{Research Model}

The present study is trying to examine the relationship between emotional intelligence and job satisfaction. Earlier research has shown that a positive relationship exists between the two constructs. However, almost all of these researches have been carried out in western countries. Hence, the present study is an attempt to explore the relationship between emotional intelligence and job satisfaction in higher education institution in Malaysian context.

Literature review showed that emotions have a significant impact on one's attitude and behavior. Emotionally intelligent people are assumed to be better able to handle stress generated from their careers and are more to be expected to experience positive emotional states for the most part of the time. They are also more likely to be able to build constructive and productive relationships with others such as customers, colleges, peers, clients, managers (Robbins, 2005). 
The Relationships Between the Emotional Intelligence and Job Satisfaction: Emprical Findings From Higher Education Institution in Malaysia

The dependent variable is the job satisfaction, which is the main concern for the present study, and the three independent variables are the appraisal of emotions in oneself and others, the regulation of emotions in oneself and others, and finally, the utilization of emotions to facilitate thinking.

These three dimensions of emotional intelligence have been conceptualized based on the framework of Salovey and Mayer (1997) is suggested to influence job satisfaction. The conceptual framework of this research is illustrated in the figure below. The purpose of the research is to discover the various dimensions in emotional intelligence that contributes to customer satisfaction. The research model developed on the basis of theoretical framework is shown below (see Figure 1)

Figure 1:

Research Model of EI and job satisfaction.

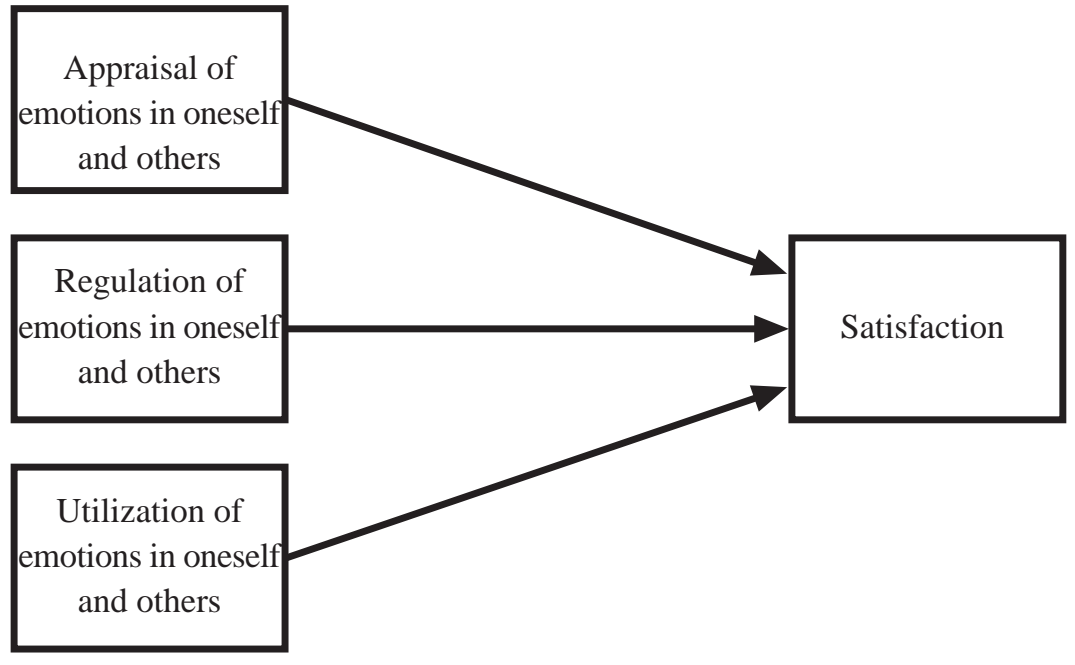

Based on the theoretical framework as above, a number of hypotheses are derived. The following hypotheses were developed for this study.

H1: There is a significant association between appraisal of emotions in oneself and other, regulation of emotions in oneself and other and utilization of emotions in oneself and others with job satisfaction.

$\mathrm{H} 2$ : The three dimensions of emotional intelligence (appraisal of emotions in oneself and other, regulation of emotions in oneself and other and utilization of emotions in oneself) positively effect the perceived job satisfaction.

\section{METHODLOGY}

\subsection{Research Design}

This is an exploratory research study, as its major purpose was to gain a better understanding of the employee emotional intelligence and job satisfaction. Survey-based methods were used to collect detailed information regarding the characteristics of the employees in their respective schools 


\subsection{Research Population and sampling}

There are a total of 750 employees in the schools of UniMap. In this study, probability sampling was used because the elements in the population have some known chance or probability of being selected as sample subjects.

According to Krejcie and Morgan (1970) when in sample size determination and various variables are under study of investigation, it is therefore difficult to determine the sample size with precision and confidence level. Therefore they had created a table of sample population and the sample size as rule of thumb to ensure that the sample size of the said population would be able to generalize the study findings (as cited in Sekaran 2000, p. 295). Therefore, 254 respondents were the samples in this study. However only 120 usable questionnaires (a return rate of 66 percent) received for this study.

\subsection{Instrumentation}

There are two questionnaires used in the present study. The first questionnaire for EI is adopted from a study by Schutte, Malouff, Hall, Haggerty, Cooper, Golden, \& Dornheim, (1998), who have developed the questionnaire on the basis of theory presented by (Mayer $\&$ Salovey, 1997) and the second questionnaire for job satisfaction is adopted from a study by Schriesheim and Tsui (1980). Using these questionnaire data were collected from the drawn sample and statically processed.

Questionnaire is a formalized set of questions for obtaining information from respondent. The questionnaire is divided into 3 parts. The first part of the questionnaire is the demographic data of the respondents which includes general questions on the gender, age, race, and marital status. Part II includes questions about the, occupation, and working experience. Part III is consisting of 13 items measuring appraisal of emotions in the self and others. Part VI consisting of 10 items measuring regulation of emotions in the self and others, and part $\mathrm{V}$ consisting of 10 items measuring utilization of emotions to facilitate thinking. The three parts (III, IV, and V) are with five point scale answers ranging from (1=strongly disagree) to ( $5=$ strongly agree). Lastly, part VI consists of 6 items measuring job satisfaction, with five point scale answers varying from ( $1=$ very dissatisfied) to (5=very satisfied).

\subsection{Reliability Testing}

Reliability testing was done to test the appropriateness of questionnaire used in this study. In this study, reliability test employed the used of Cronbach Alpha testing as it is the most frequently used reliability test tool by social researchers. The overall Cronbach Alpha reliability coefficient for 39 items is over .80 but less than.9, which is highly acceptable. According to Hair, Babin, Money and Samouel (2003), the reliability analysis scale can be accepted if the Cronbach Alpha coefficient is between 0.6 and 1.0., where on the scale reliability score range .8 to $<9$ is very good and reliability score .9 is excellent (p.172). The following reliability scores of the variables computed in this study and the score is presented in Table I.

Table I:

Reliability Scores

\begin{tabular}{|l|c|c|}
\hline Variables & $\begin{array}{c}\text { Number } \\
\text { of items }\end{array}$ & $\begin{array}{c}\text { Reliability } \\
\text { Score }\end{array}$ \\
\hline Appraisal and expression of emotions of self and other & 13 & .89 \\
\hline Regulations of emotions of self and other & 10 & .85 \\
\hline Utilization of emotions of self and other & 13 & .89 \\
\hline Job satisfaction & 6 & .83 \\
\hline
\end{tabular}


The Relationships Between the Emotional Intelligence and Job Satisfaction: Emprical Findings From Higher Education Institution in Malaysia

\subsection{Data Analysis}

In this study, descriptive analyses were carried out to describe the profile of respondents. For this study, Pearson correlation test was used to inspect whether job satisfaction has significant relationship with three dimensions emotional intelligence. In this study multiple regressions was also used to find out which variable of emotional intelligence most dominantly influences the job satisfaction.

\section{ANALYSIS AND FINDINGS}

\subsection{Background of the UNIMAP Employees}

Frequencies, means, and standard deviations for all variables were calculated, to obtain a general profile of the distribution.

The overall summary profile of the participating university employees in this survey based study, are presented in Table II.

Table: II

Background of Respondents

\begin{tabular}{|l|c|c|l|c|c|}
\hline Variable (S) & Frequency & \%age & & Frequency & \%age \\
\hline Gender & & & Marital Status & & \\
\hline Male & 74 & 61.7 & Married & 73 & 60.8 \\
\hline Female & 46 & 38.3 & Unmarried & 45 & 37.5 \\
\hline & & & Divorced/Separated & 2 & 1.6 \\
\hline Ethnic Origin & & & Departments & & \\
\hline Malay & 64 & 53.3 & Finance/Accounting & 30 & 25.0 \\
\hline Indian & 31 & 25.8 & Admissions/Marketing & 43 & 35.8 \\
\hline Chinese & 25 & 20.8 & Library & 36 & 30.0 \\
\hline & & & Administration/HR & 11 & 9.2 \\
\hline Highest Qualification & & & Working Experience & & \\
\hline Diploma & 16 & 13.3 & $<1$ Years & 36 & 30.0 \\
\hline Bachelor Degree & 53 & 44.2 & 2 - 5 Years & 47 & 39.2 \\
\hline Master Degree & 44 & 36.7 & 6 - 10 Years & 37 & 30.8 \\
\hline Ph.D Degree & 7 & 5.8 & & & \\
\hline Age & Minimum & & Maximum & Mean & \\
\hline & 19 & & 55 & 35.95 & \\
\hline
\end{tabular}

The overall profile of the participating employees 'demographic characteristics, presented in Table II. Out of 120 respondents, $74(61.7 \%)$ were male and $46(38.3 \%)$ were female employees representing almost all the major department excluding faculties or teaching personnel in the university. The distribution of the departmental representation were mainly from admission/marketing department, which represented $43(35.8 \%)$ respondents followed by $36(30 \%)$ respondent from Library, $30(25 \%)$ and $11(9.2 \%)$ respondents from Finance/accounting and administration/HR respectively.

The distribution of ages of the respondent ranged from 19 to 55, with a mean of 35.5 years. Many $(44.2 \%)$ of the participating respondent were holding a bachelor degree, Masters 
degree (36.7\%), 5.8\% were achieved a PhD degree while diploma holders were $13.3 \%$. Most of the participating employees were Malay (53.3\%), Indian Malaysian were 28.8 percent, while 20.8 percent were Chinese Malaysian. The majority $73(60.8 \%)$ of the respondent were married; wile 45 employees $(37.5 \%)$ were unmarried while 2 respondents $(1.7 \%)$ were either divorced or separated.

\subsection{The Relationship between EI and JS}

Hypothesis one examined the association and the nature of relationship between job satisfaction and the three dimension of emotional intelligence, appraisal of emotions of self and other (Appraisal), regulations of emotions of self and others (Regulations) and utilization of emotions of self and other(Utilization)

Table III Hypothesis:

One - Correlations analysis

Emotional Intelligence - Job Satisfaction

\begin{tabular}{|c|c|c|c|c|}
\hline & $\begin{array}{c}\text { Job } \\
\text { Satisfactio }\end{array}$ & Appraisal & Regulations & Utilization \\
\hline Job Satisfaction & 1 & $.786 * *$ & $.842 * *$ & $.890 * *$ \\
\hline Appraisal & $.786 * *$ & 1 & $.793 * *$ & $.666^{* *}$ \\
\hline Regulations & $.842 * *$ & $.793 * *$ & 1 & $.734 * *$ \\
\hline Utilization & $.890 * *$ & $.666^{* *}$ & $.734 * *$ & 1 \\
\hline
\end{tabular}

** Correlation is significant at the 0.01 level (2-tailed)

Analysis of the data resulted from the Pearson correlation analysis (see Table III), indicates that as expected overall job satisfaction is positively correlated with the three component of emotional intelligence and the association is significant at the 0.01 level, indicates that the association is highly significant and the relationship is positive.

The correlation analysis also reveals that the association is highly significant and the strength of the association between independent and dependent variables are very strong between job satisfaction and the three component of emotional intelligence. The value of coefficient (r) determines the strength of the association and is very strong and positive between utilization, regulations and job satisfaction (.890), (.849) respectively. However as compare to utilization and regulations the association is somewhat at moderately strong between appraisal and job satisfaction (.786). Therefore hypothesis one is failed to be rejected i.e. supported.

The findings of the correlation analysis imply that employee's level of greater emotional intelligence may lead to higher job satisfaction and perceived great self motivation among the non faculty staff in University Malaysia Perlis.

\subsection{Test of Multicollinearity}

One necessary requirement in employing multiple regression analysis is to test for the collinearity of the independent variables (Hair et. al 2003). Collinearity refers to the case of two explanatory variables that are perfectly correlated while the term multicollinearity is used to refer to collinear relations between more than two independent variables. Multicollinearity may have devastating effects on regression statistics to the extent of interpreting them useless, even highly misleading (Pedhazur, 1997). Since multicollinearity could cause problems in interpreting regression analysis, it was prudent to test the multicollinearity of the explanatory (independent) variables to determine whether or not independent variables in this study were highly correlated to each other once added into the regression model. The variance inflationary factor (VIF) for each explanatory variable was used in this study as suggested by Bersenson et al. (2004). 
The Relationships Between the Emotional Intelligence and Job Satisfaction: Emprical Findings From Higher Education Institution in Malaysia

When the result of variance inflationary factor (VIF) in each independent variable is equal to 0 , this means that theses variables are uncorrelated to each other. There will be too much correlation between the independent variables if variance inflationary factor (VIF) is greater than 5 (Hair, Andersdon, Tatham \& Black, 1992). From the result of multicollinearity diagnostics test of this study (See Table IV), it is suggested that independent variables in this study were not highly correlated with each other. Therefore this requirement for employing regression analysis techniques has been fulfilled. Table IV shows the result of this test.

Table IV:

Test of Multicollinearity

\begin{tabular}{|l|l|l|}
\hline Variables & Label & VIF \\
\hline Appraisal & Appraisal & 2.31 \\
\hline Regulation & Regulation & 3.39 \\
\hline Utilization & Utilization & 2.10 \\
\hline
\end{tabular}

\subsection{The Effect of emotional intelligence on job satisfaction (Hypothesis Two)}

While correlation analysis of this study, indicates the relationship and the strength between the explanatory variables and the dependent variable in hypothesis one confirmed the positive yet significant very strong relationship among the independent and dependent variables in the model of the study.

To test the hypothesis 2 multiple regression analysis were adopted for the regression model to estimates the variance explained onto job satisfaction by three components of emotional intelligence.

Three components of emotional intelligence (Appraisal, regulation and utilization) were included in the regression model to calculate the effects of variance caused on the job satisfaction by these three emotional intelligence variables.

First the multiple regression analysis was employed to test the overall effect of the three emotional intelligence (Appraisal, regulation and utilization) (independent variable) on job satisfaction (dependent variable). The results are shown in table $\mathrm{V}$

Table V:

Overall Influence of EI on Job Satisfaction

\begin{tabular}{|c|c|c|c|c|c|}
\hline R & R Square & Adjusted R Square & Std. Error of the Estimates & F & Sig.F \\
\hline .905 &. .818 & .813 & .24943 & 173.939 & .000 \\
\hline
\end{tabular}

The results from Table $\mathrm{V}$, indicate that the multiple regression coefficients (R) of EI factors and the job satisfaction is .905 and the adjusted $\mathrm{R}$ square is .813. The value of $\mathrm{F}$ is 173.939 $(\mathrm{P}<0.05)$.

Therefore, from the regression analysis findings indicate that 81.3 percent of the variance (adjusted R Square) of job satisfaction has been significantly explained by the three factors of emotional intelligence (Appraisal, regulation and utilization). Thus the results in this study support the alternative hypothes is that three factors of emotional intelligence (Appraisal, regulation and utilization) significantly influence the job satisfaction in the University Malaysia Perlis.

However in the regression analysis beta values of each independent variable signify the 
contribution and influence on the job satisfaction was addressed and the results are shown in Table VI.

Table VI:

Influence of each EI factor on Job Satisfaction.

\begin{tabular}{|l|c|c|c|c|}
\hline Independent Variables & $\begin{array}{c}\text { Std. } \\
\text { error }\end{array}$ & Std.beta & $\mathrm{t}$ & Sig.t \\
\hline Appraisal & .084 & .484 & 7.28 & .000 \\
\hline Regulations & .072 & .350 & 4.805 & .000 \\
\hline Utilization & .058 & .147 & 2.47 & .015 \\
\hline
\end{tabular}

Dependent variable: job satisfaction

From the result presented in table VI, appraisal appeared as the strongest explanatory variable with standardized beta of .484 . This is followed by regulations with a standardized beta of .350 and utilization with a beta value of .147 .

A further analysis was performed to examine that how these three variables; customer orientation, competitor and interfunational coordination individually and jointly contribute to R Square value or the total explanatory power of the regression model. The result of step wise regression analysis is shown in table VII for the overall effect of the three variables.

Table VII:

The overall influence (effect) of appraisal, regulations and utilization on Job satisfaction

\begin{tabular}{|c|c|c|c|c|c|}
\hline R & R Square & Adjusted R Square & Std. Error of the Estimates & F & Sig.F \\
\hline .905 &. .818 & .813 & .24943 & 173.939 & .000 \\
\hline
\end{tabular}

The results of the stepwise multiple regression analysis indicates that multiple regression coefficients (R) of appraisal, regulations and utilization on job satisfaction is. 905 and the adjusted $\mathrm{R}$ square is .813. Therefore, the findings confirmed and suggested that the overall 81.3 percent of the variance (adjusted $\mathrm{R}$ square) in job satisfaction has been significantly explained by theses three factors of emotional intelligence influence the job satisfaction of non teaching staff in University Malaysia Perlis.

Table VIII.

Influence of each variable on Job Satisfaction

\begin{tabular}{|l|c|c|c|c|}
\hline Independent Variables & $\begin{array}{c}\text { Adjusted R } \\
\text { Square }\end{array}$ & Std.beta & Beta & Sig.t \\
\hline Appraisal & .737 & & .484 & .000 \\
\hline Regulations & .805 & .069 & .350 & .000 \\
\hline Utilization & .13 & .010 & .147 & .015 \\
\hline
\end{tabular}

The result of stepwise multiple regression analysis (see Table VIII) indicates that appraisal have the highest standardized beta value (.484) and contributed 73.7 percent (adjusted $R$ square $=.737$ ) to the variance of job satisfaction. Regulations also have significant influence on the job satisfaction with the standardized beta value of .350 and contributed approximately 6.9 percent $(\mathrm{R}$ Square change $=.069)$ to the variance of job satisfaction. Utilization however also significantly influences to the variance of the job satisfaction with relatively low beta 
value of .147 and estimated approximately 1 percent variance on job satisfaction. The result of this hypothesis (Table VII) further imply that appraisal with the greater beta value of (.484) is one of the most stronger predictor of job satisfaction and therefore appraisal influence largely to job satisfaction of non teaching staff. Regulations and utilization are also appeared to be significantly effect the employee's job satisfaction. This implies that job satisfaction of employees in the University Malaysia Perlis appraisal, regulations and utilization are crucial to for job satisfaction for job satisfaction. Therefore the result of this hypothesis indicates that a hypothesis 2 is also supported.

The following significant variables are shown below which are the significant predictor variables for Employee's Job Satisfaction.

\begin{tabular}{|l|l|l|}
\hline Predictor variables & Beta & $\mathrm{p}$ \\
\hline Appraisal & .484 & .000 \\
\hline Regulations & .350 & .000 \\
\hline Utilization & .147 & .015 \\
\hline \multicolumn{2}{|l}{} \\
\hline Adjusted R Square $=.817 \quad \mathrm{~F}=173.939, \mathrm{p}<0.005$ \\
\hline
\end{tabular}

\section{DISCUSSION}

Hypothesis one was tested the association and strength of association among the four variables in this study. To examine the association and relationship, a Pearson correlation matrix indicated that job satisfaction is significantly positively correlated with the appraisal of emotions, regulations of emotion and also with the utilization of emotions. The data also indicated that the association among the variables are certainly positively correlated as expected and strength of association is vary from high to very high which also further confirmed the assumption that the perceive job satisfaction would have stronger and positive relation with the three components of emotional intelligence. This also indicates that the association between the emotional intelligence and job satisfaction has been proven as it has been proven in various previous studies. Therefore it can be concluded that job satisfaction and dimensions of EI are positively related and if firms need to improve the perceived jobs satisfaction among employees at work place, they should ensure that the employees do aware of their EI and exercise their emotional intelligence.

Further the results of hypothesis 2 imply that appraisal is one of the stronger predictor job satisfaction and therefore appraisal influence largely to job satisfaction of non teaching staff. Regulations and utilization are also appeared to be significantly effect the employee's job satisfaction. This implies that job satisfaction of employees in the University Malaysia Perlis emotional intelligence (appraisal, regulations and utilization) are crucial for job satisfaction.

\section{CONCLUSION AND RECOMMENDATION}

To conclude the overall study in a simple manner, that the study findings are important contribution to the body of knowledge in term of identification of a positive relationship between the emotional intelligence and job satisfaction in an university work setting.

Job satisfaction is certainly the hottest issues in the management research. Job satisfaction has been researched in different industrial environment and also at different level of employee's roles and responsibilities dimensions. However the current management and organizational behavior research has turned its focused on emotional intelligence to cope of the ability of people to know their emotions and understand others emotions to cope 
with environmental demands and pressures. This study therefore confirmed that EI has positive effect on job satisfaction of employees at university. Further to this a university administration and HR policies could have been developed to ensure that EI factor must be incorporated particularly in one of the most crucial process of staffing and performance appraisal and other HR Functions. Employing with a high level of emotionally intelligent employee would certainly an asset to the organization.

On the basis of the finding of the study and overall discussion drawn from the findings, I would like to make several future recommendations to the university perils may be in terms of development of policy document for a broader university strategic vision.

\subsection{The HR Policy}

The most important recommendation or suggestion is made in terms of HR strategic policy of the university. The policy therefore clearly states that the selection of the employees at University should not discriminate on the gender biases that are the male and female potential candidates should have been given equal employment opportunity. Since the greater job satisfaction is one of the crucial factor of higher productivity, lower turn over, lower absenteeism, collectively greater organization development therefore all key factor should have been identified during the recruitment and selection process of the University. The most importantly university HR policy should now focus on

1. Compensation policies

2. Improvement of supervisor and staff relationship

3. Improvement of environment where coworker's relationship can be improved.

4. Collectively this also leads to fair and effective communication policy in the University.

\subsection{Selection Criteria Testing}

On the basis of the finding from this study I would like to focus on the selection standards , which are one of the most important factors or determinants of selecting individual such as qualification, skills, intelligence, etc. however since this study reveals that there were highly positive correlation between the job satisfaction and dimensions of EI therefore it is suggested that if university would introduce EI tests and candidates with better EI score may consider for potential hiring, This would certainly be proven to higher job satisfaction and thus greater performance of the employees. The university can develop psychometric EI test as they may had already developed for IQ and then test the potential candidates EI level and do select those who have better EI score on tests.

\subsection{Organization Change/Redesining}

This is one of the suggestion I would like to make in terms of achieving an optimum level of job satisfaction of the employees with greater emotional intelligence therefore, this study finding tells us that there is still need for improving the EI level of the existing employees in the university because the finding do not allow us to explain the fact that employees in the university do have an EI level at higher level rather they are at moderate level therefore an organization change strategy toward providing a much more decentralize working environment which provide opportunity in fair and fearless communication channels among employees and the top managers which ensure that people would have freely able to communicate and express their emotion, use them and regulate to exhibit functional behavior which would result in greater job satisfaction and thus better productivity and higher performance.

\subsection{Learning Organization}

Fundamentally this is relatively new concept of the Management discuss extensively in 
the literature of organization behavior (Robbins, 2005). This is a philosophy which ensures that organization is able to adopt changes and support people for suggestions in how to improve the organization effectiveness. This philosophy is therefore based on sharing of knowledge, expertise, values, and beliefs among the employees at the work place. The learning organization is therefore, would certainly an enabler to improve the EI of the employees which encourage the people at work place to effectively communicate each other and do contribute in the organizational development through better performance by encouraging creativity, motivation and innovation at workplace.

\section{LIMITATIONS AND FURTHER RESEARCH OPPORTUNITY}

The limitation of this study is the sample size, since the sample size is too small to generalize the overall study therefore the result findings may be understood with cautions and should therefore limit to the university Perlis environment.

The second limitation as far as the research design is concerned, in term of questionnaire used in this study to capture the EI. Since there are few more widely used EI construct (Golman et al, 2002) developed a 139 items construct of most of the dimension of EI is also in use in the organization behavior studies in terms of EI and to measure its several dimensions. Therefore one of the issues which limit this research study findings is using only three dimensions instead of other dimension mentioned by (Golman et al, 2002) to capture most of the other dimensions of emotional intelligence.

Further research can be done on the comparative study of IQ and EQ of employees at work place and combined effect of IQ and EI on job satisfaction. This would certainly an important contribution to the body of knowledge, which would determine how these two effect job satisfaction at work place taking into again demographic factor such as marital status and sexual orientation of employees.

Further more, researchers can also look for the other control variables and introduce those onto their regression model such as age, year of experience or marital status to know how these factors influence on the job satisfaction when controlled the model through these variables in the presence of EI as independent variables etc.

Since this study does not revealed that how differently people at different department shows their emotions and had relationship with job satisfaction, therefore a research design may need to be enhanced in term of cross functionality or even cross racial level of employees and their perceived job satisfaction and its association to emotional intelligence.

There could be various approaches and many opportunity is available for academics as well as managerial research in the area of job satisfaction and the EI, the only requirement is however the understating the contextual variables of EI to take into account in the study that is how EI has effected by other variables such as family conflict, a divorced employees or organization internal environment etc.

\section{REFERENCES}

Bar-On, R. Handley, R., \& Fund, S. (2006). The impact of emotional intelligence on performance. In V. U. Druskat, F. Sala, \& G. Mount (Eds.), Linking emotional intelligence and performance at -work: Current research evidence with individuals and groups. Mahwah, NJ: Erlbaum.

Boyatzis, R. \& McKee, A. (2005). Resonant leadership. Boston, MA: Harvard Business School Press.

Ciarrochi, J. \& Godsell, C. (2006). Mindfulness-based emotional intelligence: Research and training. In V. U. Druskat, F. Sala, \& G. Mount (Eds.), Linking emotional intelligence and performance at work: Current research evidence with individuals and groups. 
Mahwah, NJ: Erlbaum.

Dent, J. (2001). Built to serve: An integrated structure for leading in organizational change. Master thesis, University of the Pacific.

Dormann, C. \& Zapf, D. (2001). Job satisfaction: A meta-analysis of stabilities. Journal of Organizational Behavior, 22,483504.

Druskat, V. U., Sala, F. \& Mount, G. (2006). Linking emotional intelligence and performance at work: Current research evidence with individuals and groups. Mahwah, NJ: Erlbaum.

Fisher, C. D. (2006). Mood and emotions while working: Missing pieces of job satisfaction. Journal of Organizational Behavior, 21, 185-213.

George, J.M. (2000). Emotions and leadership: the role of emotional intelligence. Human Relations, 53 (8), 1027-1055.

Gerhart, B. (2005). The (affective) dispositional approach to job satisfaction: Sorting out the policy implications. Journal of Organizational Behavior, 26, 79-97.

Goleman, D. ( 1995). Emotional intelligence. New York: Bantam Books.

Goleman, D. (1996). Emotional Intelligence: Why It Can Matter More Than IQ. Bloomsbury: London.

Goleman, D. (1998). Working with emotional intelligence. New York: Bantam Books

Goleman, D. (1999). Emotional competence. Executive Excellence, 16 (4), 19-29.

Goleman, D., Boyatzis, R., \& McKee, A. (2002). Primal leadership: Learning to lead with emotional intelligence. Boston: Harvard Business School Press.

Hair, J., Babin, B., Money, A., \& Samouel, P.( 2003). Essential of Business Research Methods. USA : John Weilly \& Sons.

Hair, J., Anderson, R., Tatham, R., \& Black, W. (1992). Multivariate Data Analysis with Readings. Prentice-Hall, Englewood Cliffs: NJ

Harrod, N. R \& Scheer. S. D (2005). An exploration of adolescent emotional intelligence in relation to demographic characteristics. Adolescence, 40 (159) 503-512.

Heller, D., Judge, T., \& Watson, D. (2002). The confounding role of personality and trait affectivity in the relationship between job and life satisfaction. Journal of Organizational Behavior, 23, 815-835.

Herzberg, F., Mauser, B. \& Snyderman, B. (1959). The motivation to work. New York: John Wiley.

Krejcie, R. V., \& Morgan, D. W. (1970). Determining sample size for research activities. Educational and Psychological Measurement, 33, 607-610.

Locke, E. A. (1976). The nature and causes of job satisfaction. In M.D. Dunnette (Eds.): Handbook of Industrial and Organizational Psychology. Chicago: Rand McNally.

Lopes, P., Cote, S., \& Salovey, P. (2006). An ability model of emotional intelligence: Implications for assessment and training. In V. U. Druskat, F. Sala, \& G. Mount (Eds.), Linking emotional intelligence and performance at work: Current research evidence with individuals and groups. Mahwah, NJ: Erlbaum.

Mayer, J.D. \& Salovey. (1997). What is emotional intelligence? In P. Salovey, \& D. Sluyter, (Eds.), Emotional development and emotional intelligence: Implications for education (pp. 3-31). More than a social virtue: Public trust among organizations' most valuable assets. (2003, Apr/May). Communication World, 20, 10-12.

Mount, Q. (2006). The role of emotional intelligence in developing international business capability: EI provides traction. In V. U. Druskat, F. Sala, \& G. Mount (Eds.), Linking emotional intelligence and performance at work: Current research evidence with individuals and groups. Mahwah, NJ: Erlbaum.

Pedhazur, E. J. (1997). Multiple Regression in Behavioral Research (3rd ed.). Orlando, FL: Harcourt Brace

Rapisarda, B. A, (2002). The impact of emotional intelligence on work team cohesiveness and performance. International Journal of Organizational Analysis, 10 (4), 363-380.

Robbins, S. (2005). Organizational behavior. Upper Saddle River, New Jersey: Pearson Prentice Hall.

Rosete, D \& Ciarrochi. J, (2005). Emotional intelligence and its relationship to workplace performance outcomes of leadership effectiveness. leadership and organization development, 26 (5/6), 388-400.

Salovey, P. \& Mayer, J.D (1990), Emotional intelligence, Imagination, Cognition and 
The Relationships Between the Emotional Intelligence and Job Satisfaction: Emprical Findings From Higher Education Institution in Malaysia

Personality, 9, 185-211.

Schriescheim, C., \& Tsui, A. S., (1980) "Development and validation of a short satisfaction instrument for use in survey feedback interventions." Paper presented at the Western Academy of Management meeting.

Schutte, N.S., Malouff, J.M., Hall, L.E., Haggerty, D.J., Cooper, J.T., Golden, CJ. \& Dornheim, L. (1998). Development and validation of a measure of emotional intelligence, Personality and Individual Differences, 25, 167-77.

Sekaran, U. (2000). Research Methods for Business: A Skill-building Approach (3rd ed.). New York, NY: John Wiley \& Sons,

Staw, B. M. \& Cohen-Charash, Y. (2005). The dispositional approach to job satisfaction: More than a mirage, but not yet an oasis. Journal of Organizational Behavior, 26, 5978

Staw, B. M. (2004). The dispositional approach to job attitudes: An empirical and conceptual review. In B. Schneider, \& B. (Eds.), Personality and organization. Mahwah, NJ: Erlbaum.

Vakola. M., Tsausis. L., \& Nikolaou, L. (2004). The role of emotional intelligence and personality variables on attitudes toward organizational change. Journal of Managerial Psychology, 19 (1/2), 88-103.

Van, M. J., \& Kunda, G. (1989). Real feelings: emotional expression and organizational culture. Research in Organizational Behavior, 11, 43-103.

Wasielewski, P.L. (1985).The emotional basis of charisma. Symbolic Interaction, 8, $207-$ 222

Zeider, M., Matthews G., Roberts, R. (2004). Applied Psychology: An International Review, 53371-399. 